\title{
Variable Head Hydrothermal Generation Scheduling Using Genetic Algorithm and Constriction Factor Based Particle Swarm Optimization Technique
}

\author{
M.M. Salama, M.M. Elgazar, S.M. Abdelmaksoud, And H.A. Henry \\ ${ }^{1,3,4}$ Department of Electrical Engineering, Faculty of Engineering Shoubra, Benha University, Cairo, Egypt \\ ${ }^{2}$ Department of Electrical Engineering, Azhar University, Cairo, Egypt
}

\begin{abstract}
In this paper, a genetic algorithm and constriction factor based particle swarm optimization technique are proposed for solving the short term variable head hydrothermal scheduling problem with transmission line losses. The performance efficiency of the proposed techniques is demonstrated on hydrothermal test system comprising of two thermal units and two hydro power plants. the simulation results obtained from the constriction factor based particle swarm optimization technique are compared with the outcomes obtained from the genetic algorithm to reveal the validity and verify the feasibility of the proposed methods. The results show that the constriction factor based particle swarm optimization technique give the same results as obtained by genetic algorithm but the computation time of the constriction factor based particle swarm optimization method is less than genetic algorithm.
\end{abstract}

Keywords: - Hydrothermal Generation Scheduling, Genetic Algorithm (GA), Particle Swarm Optimization (PSO), Constriction Factor (CF)

\section{INTRODUCTION}

The hydrothermal generation scheduling plays an important role in the operation and planning of a power system. Since the operating cost of thermal power plant is very high compared to the operating cost of hydro power plant, the integrated operation of the hydro and thermal plants in the same grid has become the more economical [1]. The main objective of the short term hydro thermal scheduling problem is to determine the optimal generation schedule of the thermal and hydro units to minimize the total production cost over the scheduling time horizon (typically one day or one week) subjected to a variety of thermal and hydraulic constraints. The hydrothermal generation scheduling is mainly concerned with both hydro unit scheduling and thermal unit dispatching. The hydrothermal generation scheduling problem is more difficult than the scheduling of thermal power systems. Since there is no fuel cost associated with the hydro power generation, the problem of minimizing the total production cost of hydrothermal scheduling problem is achieved by minimizing the fuel cost of thermal power plants under the constraints of water available for the hydro power generation in a given period of time [2]. In short term hydrothermal scheduling problem, the generating unit limits and the load demand over the scheduling interval are known. Several mathematical optimization techniques have been used to solve short term hydrothermal scheduling problems [3]. In the past, hydrothermal scheduling problem is solved using classical mathematical optimization methods such as dynamic programming method [4-5], lagrangian relaxation method [6-7], mixed integer programming [8], interior point method [9], gradient search method and Newton raphson method [2]. In these conventional methods simplifying assumptions are made in order to make the optimization problem more tractable. Thus, most of conventional optimization techniques are unable to produce optimal or near optimal solution of this kind of problems. The computational time of these methods increases with the increase of the dimensionality of the problem. The most common optimization techniques based upon artificial intelligence concepts such as evolutionary programming [10-11], simulated annealing [12-13], differential evolution [14], artificial neural network [15-16], genetic algorithm [17 -19] and particle swarm optimization [20-24] have been given attention by many researchers due to their ability to find an almost global or near global optimal solution for short term hydrothermal scheduling problems with operating constraints. Major problem associated with these techniques is that appropriate control parameters are required. Sometimes these techniques take large computational time due to improper selection of the control parameters.

The PSO is a population based optimization technique first proposed by Kennedy and Eberhart in 1995. In PSO, each particle is a candidate solution to the problem. Each particle in PSO makes its decision based on its own experience together with other particles experiences. Particles approach to the optimum solution through its present velocity, previous experience and the best experience of its neighbors [28]. Compared to other evolutionary computation techniques, PSO can solve the problems quickly with high quality solution and stable convergence characteristic, whereas it is easily implemented. 
The genetic algorithm (GA) is a stochastic global search and optimization method that mimics the metaphor of natural biological evolution such as selection, crossover and mutation. GA is started with a set of candidate solutions called population (represented by chromosomes). At each generation, pairs of chromosomes of the current population are selected to mate with each other to produce the children for the next generation. The chromosomes which are selected to form the new offspring are selected according to their fitness. In general, the chromosomes with higher fitness values have higher probability to reproduce and survive to the next generation. While the chromosomes with lower fitness values tend to be discarded. This process is repeated until a termination condition is reached (for example maximum number of generations). Most of the GA parameters are set after considerable experimentation and the major drawback of this method is the lack of a solid theoretical basis for their setting.

\section{PROBLEM FORMULATION}

The main objective of short term hydro thermal scheduling problem is to minimize the total fuel cost of thermal power plants over the optimization period while satisfying all thermal and hydraulic constraints. The objective function to be minimized can be represented as follows:

$$
\mathrm{FT}=\sum_{\mathrm{t}=1}^{\mathrm{T}} \sum_{\mathrm{i}=1}^{\mathrm{N}} \mathrm{ntFit}(\text { Pgit })
$$

In general, the fuel cost function of thermal generating unit $i$ at time interval $t$ can be expressed as a quadratic function of real power generation as follows:

$$
\operatorname{Fit}(\text { Pgit })=\mathrm{aiP}^{2} \text { git }+ \text { biPgit }+\mathrm{ci}
$$

Where $P_{g i t}$ is the real output power of thermal generating unit $i$ at time interval $t$ in (MW), Fit (Pgit) is the operating fuel cost of thermal unit i in $(\$ / h r), F_{T}$ is the total fuel cost of the system in $(\$), T$ is the total number of time intervals for the scheduling horizon, $\mathrm{nt}$ is the numbers of hours in scheduling time interval $\mathrm{t}, \mathrm{N}$ is the total number of thermal generating units, $\mathrm{ai}_{\mathrm{i}} \mathrm{b}_{\mathrm{i}}$ and ci are the fuel cost coefficients of thermal generating unit i.

The minimization of the objective function of short term hydrothermal scheduling problem is subject to a number of thermal and hydraulic constraints. These constraints include the following:

\section{1) Real Power Balance Constraint:}

For power balance, an equality constraint should be satisfied. The total active power generation from the hydro and thermal plants must equal to the total load demand plus transmission line losses at each time interval over the scheduling period.

$$
\sum_{\mathrm{i}=1}^{\mathrm{N}} \mathrm{Pgit}+\sum_{\mathrm{j}=1}^{\mathrm{M}} \mathrm{Phjt}=\mathrm{PDt}+\mathrm{PLt}
$$

Where, PDt is the total load demand during the time interval $t$ in (MW), Phjt is the power generation of hydro unit $j$ at time interval $t$ in (MW), Pgit is the power generation of thermal generating unit $i$ at time interval $t$ in (MW), $\mathrm{M}$ is the number of hydro units and PLt represents the total transmission line losses during the time interval $\mathrm{t}$ in (MW).

The total transmission line loss is assumed as a quadratic function of output powers of the generator units [29] that can be approximated in the form:

$$
\mathrm{PLk}=\sum_{\mathrm{i}=1}^{\mathrm{N}+\mathrm{M}} \sum_{\mathrm{j}=1}^{\mathrm{N}+\mathrm{M}} \mathrm{PitBij}_{\mathrm{ijt}}
$$

Where $\mathrm{B}_{i j}$ is the transmission loss coefficient matrix, Pit and Pjt are the power generation of hydro or thermal plants and $\mathrm{M}$ is the number of hydro power plants.

\section{2) Thermal Generator Limit Constraint:}

The output power generation of thermal power plant must lie in between its minimum and maximum limits. The inequality constraint for each thermal generator can be expressed as:

$$
\mathrm{Pgi}^{{ }^{\text {in }}} \leq \mathrm{Pgit} \leq \mathrm{Pgi}^{\text {max }}
$$

Where $\mathrm{Pgi}^{\mathrm{min}}$ and $\mathrm{Pgi}^{\mathrm{max}}$ are the minimum and maximum power outputs of thermal generating unit $\mathrm{i}$ in (MW), respectively. The maximum output power of thermal generator $\mathrm{i}$ is limited by thermal consideration and minimum power generation is limited by the flame instability of a boiler. 


\section{3) Hydro Generator Limit Constraint:}

The output power generation hydro power plant must lie in between its minimum and maximum bounds. The inequality constraint for each hydro generator can be defined as:

$$
\mathrm{Phj}^{\text {min }} \leq \mathrm{Phjt} \leq \mathrm{Phj}^{\text {max }}
$$

Where $\mathrm{Phj}^{\mathrm{min}}$ is the minimum power generation of hydro generating unit $\mathrm{j}$ in (MW) and $\mathrm{Phj}^{\mathrm{max}}$ is the maximum power generation of hydro generating unit $\mathrm{j}$ in (MW).

\section{4) Reservoir Storage Volume Constraint:}

The operating volume of reservoir storage limit must lie in between the minimum and maximum capacity limits.

$$
\mathrm{Vhj}^{\text {min }} \leq \mathrm{Vhjt} \leq \mathrm{Vhj}^{\text {max }}
$$

Where Vhjmin is the minimum storage volume of reservoir $\mathrm{j}$ and Vhjmax is the maximum storage volumes of reservoir j.

\section{5) Water Discharge Rate Limit Constraint:}

The water Discharge rate of hydro turbine must lie in between its lower and upper operating limits.

$$
\mathrm{qhj}^{\text {min }} \leq \mathrm{qhjt} \leq \mathrm{qhj}^{\text {max }}
$$
respectively

Where $\mathrm{qhj}^{\mathrm{min}}$ and $\mathrm{qhj}^{\max }$ are the minimum and maximum water discharge rate of reservoir $\mathrm{j}$,

\section{6) Water Availability Limit:}

For the scheduling time period, each hydro generating plant is restricted by the amount of water available in the reservoir as follows:

$$
\sum_{\mathrm{t}=1}^{\mathrm{T}} \mathrm{ntqhjt}=\mathrm{Vhj}
$$

Where qhjt is the water discharge rate of hydro unit $\mathrm{j}$ during the time interval $\mathrm{t}$ and Vhj is the volume of water stored in hydro reservoir $\mathrm{j}$.

\section{7) Water Net Head Variation:}

For variable head reservoir, the water discharge rate is a function of output power and the effective head and can be expressed according to Glimn-Kirchmayer model as follow:

$$
\mathrm{qhjt}=\mathrm{k} \psi\left(\mathrm{h}_{\mathrm{j}}\right) \varphi\left(\mathrm{Phjt}_{\mathrm{hj}}\right)
$$

Where qhjt is the water discharge rate of the reservoir $\mathrm{j}, \mathrm{k}$ is the constant of proportionality; hj is the effective head of reservoir $\mathrm{j}$ and Phjt is the output power of hydro generating unit $\mathrm{j}$ at time interval $t$.

Where $\psi$ and $\phi$ are quadratic functions and are given by:

$$
\begin{aligned}
& \psi\left(h_{j}\right)=\alpha h_{j}{ }^{2}+\beta h_{j}+\gamma \\
& \varphi\left(P_{h j t}\right)=x P_{h j t}{ }^{2}+y h_{h t}+z
\end{aligned}
$$

Where $\mathrm{x}, \mathrm{y}$ and $\mathrm{z}$ are the water discharge coefficients; $\alpha, \beta$ and $\gamma$ are positive coefficients.

Consider a hydro power plant $\mathrm{j}$ is assumed to have a small capacity vertical sided reservoir and the water elevation is assumed to be independent of natural inflow. The effective net head can be expressed as follows [2]:

$$
h j t+1=h j t+\frac{n t}{S_{j}}(\text { Ihjt-qhjt })
$$

Where hjt is the water head of the reservoir $\mathrm{j}$ during the time interval $\mathrm{t}$, Ihjt is the inflow rate to the reservoir $\mathrm{j}$ during the time interval $t$, qhjt is the water discharge rate of reservoir $j$ during the time interval $t, S j$ is the surface area of the vertical sided reservoir $\mathrm{j}$.

\section{OVERVIEW OF GENETIC ALGORITHM}

The GA is a method for solving optimization problems that is based on natural selection, the process that drives biological evolution. The general scheme of GA is initialized with a population of candidate solutions (called chromosomes). Each chromosome is evaluated and given a value which corresponds to a fitness level in problem domain. At each generation, the GA selects chromosomes from the current population based on their fitness level to produce offspring. The chromosomes with higher fitness levels have higher probability to become parents for the next generation, while the chromosomes with lower fitness levels to be discarded. After the selection process, the crossover operator is applied to parent chromosomes to produce new offspring chromosomes that inherent information from both sides of parents by combining partial sets of genes from them. The chromosomes or children resulting from the crossover operator will now be subjected to the mutation operator in final step to form the new generation. Over successive generations, the population evolves toward an optimal solution. A schematic outline of simple genetic algorithm is illustrated in figure 1. 


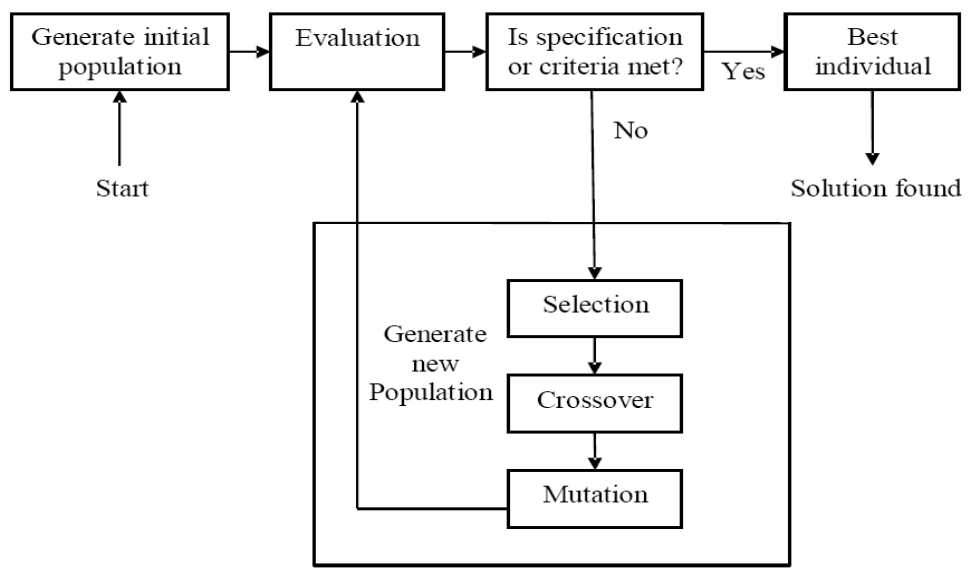

Fig.1. Schematic outline of simple genetic algorithm

The features of GA are different from other traditional methods of optimization in the following respects [25]:

- GA does not require derivative information or other auxiliary knowledge.

- GA work with a coding of parameters instead of the parameters themselves. For simplicity, binary coded is used in this paper.

- GA search from a population of points in parallel, not a single point.

- GA use probabilistic transition rules, not deterministic rules.

\section{GENETIC ALGORITHM OPERATORS}

At each generation, GA uses three operators to create the new population from the previous population:

\section{1) Selection or Reproduction}

Selection operator is usually the first operator applied on the population. The chromosomes are selected based on the Darwin's evolution theory of survival of the fittest. The chromosomes are selected from the population to produce offspring based on their fitness values. The chromosomes with higher fitness values are more likely to contributing offspring and are simply copied on into the next population. The commonly used reproduction operator is the proportionate reproduction operator. The ith string in the population is selected with a probability proportional to $\mathrm{F}_{\mathrm{i}}$ where, $\mathrm{F}_{\mathrm{i}}$ is the fitness value for that string. The probability of selecting the ith string is:

$$
P i=\frac{F i}{\sum_{j=1}^{n} F j}
$$

Where $\mathrm{n}$ is the population size, the commonly used selection operator is the roulette-wheel selection method. Since the circumference of the wheel is marked according to the string fitness, the roulette-wheel mechanism is expected to make $\mathrm{F} / \mathrm{Favg}$ copies of the ith string in the mating pool. The average fitness of the population is:

$$
\text { Favg }=\frac{\sum_{i=1}^{n} F i}{n}
$$

\section{2) Crossover or Recombination}

The basic operator for producing new chromosomes in the GA is that of crossover. The crossover produce new chromosomes have some parts of both parent chromosomes. The simplest form of crossover is that of single point crossover. In single point crossover, two chromosomes strings are selected randomly from the mating pool. Next, the crossover site is selected randomly along the string length and the binary digits are swapped between the two strings at crossover site.

\section{3) Mutation}

The mutation is the last operator in GA. It prevents the premature stopping of the algorithm in a local solution. The mutation operator enhances the ability of the genetic algorithm to find a near optimal solution to a 
given problem by maintaining a sufficient level of genetic variety in the population. This operator randomly flips or alters one or more bits at randomly selected locations in a chromosome from 0 to 1 or vice versa.

\section{4) Parameters of Genetic Algorithm (GA)}

The performance of GA depends on choice of GA parameters such as:

i. Population size (Np): The population size affects the efficiency and performance of the algorithm. Higher population size increases its diversity and reduces the chances of premature converge to a local optimum, but the time for the population to converge to the optimal regions in the search space will also increase. On the other hand, small population size may result in a poor performance from the algorithm. This is due to the process not covering the entire problem space. A good population size is about 20-30, however sometimes sizes 50-100 are reported as best.

ii. Crossover rate: The crossover rate is the parameter that affect the rate at which the process of cross over is applied. This rate generally should be high, about $80-95 \%$.

iii. Mutation rate: It is a secondary search operator which increases the diversity of the population. Low mutation rate helps to prevent any bit position from getting trapped at a single value, whereas high mutation rate can result in essentially random search. This rate should be very low.

\section{5 ) Termination of the GA}

The generational process is repeated until a termination condition has been satisfied. The common terminating conditions are:

- The algorithm reaches the specified number of generations.

- The algorithm runs for a specified amount of time.

- The best fitness value in the current population is less than or equal to the specified value.

- The best solution is not changed after a set number of generations.

- The algorithm runs for a specified amount of time with no improvement in the fitness function.

\section{GA APPLIED TO SHORT TERM HYDROTHERMAL SCHEDULING PROBLEM}

In genetic algorithm, the water discharge through the turbines during each optimization interval is used as the main control variable. In binary genetic algorithm representation, the water discharge rates for each reservoir at each time interval are represented by a given number of binary strings. In GA binary representation, the water discharge rate is used rather than the output power generation of hydro units because the encoded parameter is more beneficial for dealing with water balance constraints. The binary representation of hydro thermal coordination problem is illustrated in figure 2 .

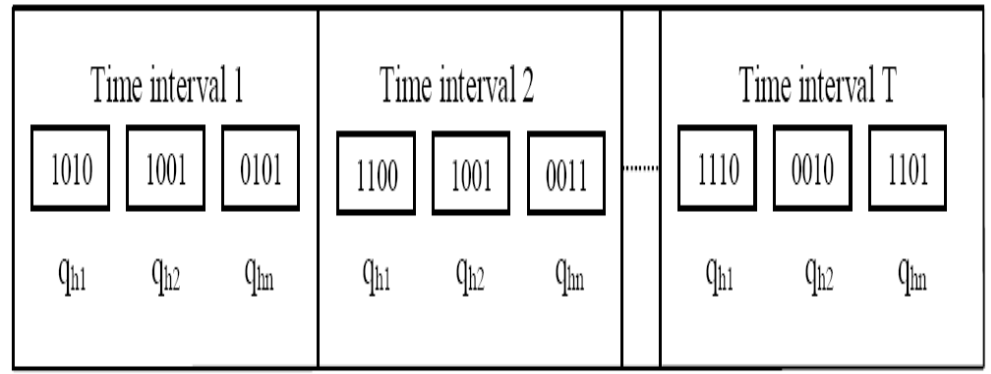

Fig.2. Binary representation of hydro thermal scheduling problem

The generated string can be converted in the feasible range by using the following equation:

$$
\mathrm{qhj}=\mathrm{qhj}^{\min }+\left(\frac{\mathrm{qhj}^{\text {max }}-\mathrm{qhj}^{\text {min }}}{2^{\mathrm{L}}-1}\right) \times \mathrm{di}
$$

Where $\mathrm{qhj}^{\mathrm{min}}$ is the minimum value of discharge rate through hydro turbine $\mathrm{j}$, $\mathrm{qhj}^{\max }$ is the maximum value of discharge rate through hydro turbine $\mathrm{j}, \mathrm{L}$ is the String length (number of bits used for encoding water discharge rate of each hydro unit) and di is the binary coded value of the string (decimal value of string).

By knowing the water discharge rate of each hydro power plant the output power of hydro power plant can be determined. The total power generations of all hydro power plants are subtracted from the total system load demand for each hour. The remaining load must be satisfied by running thermal units for each hour. An economic load dispatch problem is achieved and the fuel cost for each thermal unit over the scheduling period is calculated. 
The sequential steps of solving short term hydro thermal scheduling problem by using genetic algorithm are explained as follows:

Step 1: Read the system input data, namely fuel cost curve coefficients, power generation limits of hydro and thermal units, number of thermal units, number of hydro units, power demands, water discharge rate coefficients, amount of water available in hydro reservoir, transmission loss coefficients matrix, surface area of reservoir and initial head of reservoir.

Step 2: Select genetic algorithm parameters such as population size, length of string, probability of crossover, probability of mutation and maximum number of generations to be performed.

Step 3: Generate the initial population randomly in the binary form. The initial population must be feasible candidate solutions that satisfy the practical operation constraints of all thermal and hydro units.

Step 4: Calculate the discharge rate of each hydro unit from the decoded population by using equation (16).

Step 5: Calculate the hydro power generation of each hydro unit.

Step 6: Calculate the thermal demand by subtracting the generation of hydro units from the total load demand. The thermal demand (total load - hydro generation) must be covered by the thermal units. The thermal generations are calculated from the power balance equation given in (4).

Step 7: Calculate the output power of each thermal unit by solving economic load dispatch problem.

Step 8: evaluate the variation in water head by using equation (13).

Step 9: Evaluate the fitness value for each string in the population by using the objective function stated in equation (1).

Step 10: The chromosomes with lower cost function are selected to become parents for the next generation.

Step 11: Perform the crossover operator to parent chromosomes to create new offspring chromosomes.

Step 12: The mutation operator is applied to the new offspring resulting from the crossover operation to form the new generation.

Step 13: Update the population.

Step 14: If the number of iterations reached the maximum, then go to step15. Otherwise go to step 4.

Step15: The string that generates the minimum total fuel cost of the thermal power plants is the optimal solution of the problem.

Step 16: Print the output results and stop.

\section{PARTICLE SWARM OPTIMIZATION WITH CONSTRICTION FACTOR 1) OVER VIEW OF PARTICle SWARM Optimization}

Particle swarm optimization (PSO) is a population based stochastic optimization technique, inspired by social behavior of bird flocking or fish schooling. It is one of the most modern heuristic algorithms, which can be used to solve non linear and non continuous optimization problems. PSO shares many similarities with evolutionary computation techniques such as genetic algorithm (GA). The system is initialized with a population of random solutions and searches for optima by updating generations. However, unlike GA, PSO has no evolution operators such as mutation and crossover. The PSO algorithm searches in parallel using a group of random particles. Each particle in a swarm corresponds to a candidate solution to the problem. Particles in a swarm approach to the optimum solution through its present velocity, its previous experience and the experience of its neighbors. In every generation, each particle in a swarm is updated by two best values. The first one is the best solution (best fitness) it has achieved so far. This value is called Pbest. Another best value that is tracked by the particle swarm optimizer is the best value, obtained so far by any particle in the population. This best value is a global best and called gbest. Each particle moves its position in the search space and updates its velocity according to its own flying experience and neighbor's flying experience. After finding the two best values, the particle update its velocity according to equation (17).

$$
\mathrm{V}_{\mathrm{i}}^{\mathrm{k}+1}=\omega \times \mathrm{Vi}^{\mathrm{k}}+\mathrm{c} 1 \times \mathrm{r} 1 \times\left(\mathrm{Pbesti}^{\mathrm{k}}-\mathrm{Xi}^{\mathrm{k}}\right)+\mathrm{c} 2 \times \mathrm{r} 2 \times\left(\mathrm{gbest}^{\mathrm{k}}-\mathrm{Xi}^{\mathrm{k}}\right)
$$

Where $\mathrm{V}^{\mathrm{ik}}$ is the velocity of particle $\mathrm{i}$ at iteration $\mathrm{k}, \mathrm{X}^{\mathrm{ik}}$ is the position of particle $\mathrm{i}$ at iteration $\mathrm{k}$, $\omega$ is the inertia weight factor, $\mathrm{c} 1$ and $\mathrm{c} 2$ are the acceleration coefficients, $\mathrm{r}_{1}$ and $\mathrm{r}_{2}$ are positive random numbers between 0 and 1, Pbesti $^{\mathrm{k}}$ is the best position of particle $\mathrm{i}$ at iteration $\mathrm{k}$ and gbest ${ }^{\mathrm{k}}$ is the best position of the group at iteration $\mathrm{k}$.

In the velocity updating process, the acceleration constants $c_{1}, c_{2}$ and the inertia weight factor are predefined and the random numbers $r_{1}$ and $r_{2}$ are uniformly distributed in the range of [0,1]. Suitable selection of inertia weight in equation (17) provides a balance between local and global searches, thus requiring less iteration on average to find a sufficiently optimal solution. A low value of inertia weight implies a local search, while a high value leads to global search. As originally developed, the inertia weight factor often is decreased linearly 
from about 0.9 to 0.4 during a run. It was proposed in [26]. In general, the inertia weight $\omega$ is set according to the following equation:

$$
\omega=\omega_{\max }-\frac{\omega_{\max }-\omega_{\min }}{\text { Itermax }} \times \text { Iter }
$$

Where $\omega_{\min }$ and $\omega_{\max }$ are the minimum and maximum value of inertia weight factor, Itermax corresponds to the maximum iteration number and Iter is the current iteration number.

The current position (searching point in the solution space) can be modified by using the following equation:

$$
\mathrm{Xi}^{\mathrm{k}+1}=\mathrm{Xi}^{\mathrm{k}}+\mathrm{Vi}^{\mathrm{k}+1}
$$

The velocity of particle $\mathrm{i}$ at iteration $\mathrm{k}$ must lie in the range:

$$
\mathrm{V}_{\text {imin }} \leq \mathrm{V}_{\mathrm{i}}^{\mathrm{k}} \leq \mathrm{V}_{\text {imax }}
$$

The parameter $\mathrm{V}_{\max }$ determines the resolution or fitness, with which regions are to be searched between the present position and the target position. If $\mathrm{V}_{\max }$ is too high, the PSO facilitates a global search and particles may fly past good solutions. Conversely, if $\mathrm{V}_{\max }$ is too small, the PSO facilitates a local search and particles may not explore sufficiently beyond locally good solutions. In many experiences with PSO, $\mathrm{V}_{\max }$ was often set at 10$20 \%$ of the dynamic range on each dimension.

The constants $c_{1}$ and $c_{2}$ in equation (17) pull each particle towards Pbest and gbest positions. Thus, adjustment of these constants changes the amount of tension in the system. Low values allow particles to roam far from target regions, while high values result in abrupt movement toward target regions. Figure 3 shows the search mechanism of particle swarm optimization technique using the modified velocity, best position of particle $i$ and best position of the group.

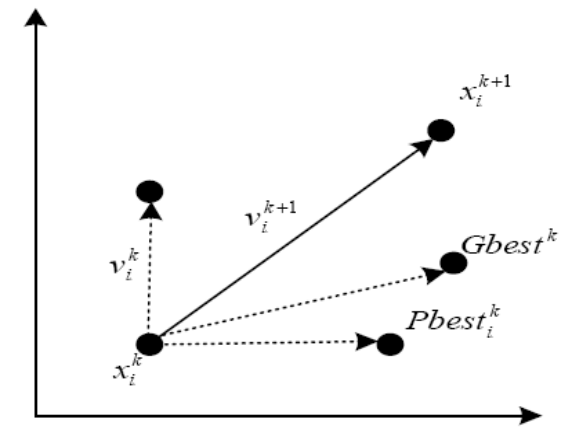

Fig.3. Updating the position mechanism of PSO technique

\section{2) Constriction Factor Approach (CFA)}

After the original particle swarm proposed by Kennedy and Eberhart, a lot of improved particle swarms were introduced. The particle swarm with constriction factor is very typical. Recent work done by Clerc [27] indicates that the use of a constriction factor may be necessary to insure convergence of the particle swarm optimization algorithm. In order to insure convergence of the particle swarm optimization algorithm, the velocity of the constriction factor approach can be represented as follows:

$$
\mathrm{V}_{\mathrm{i}}^{\mathrm{k}+1}=\mathrm{K} \times\left[\omega \times \mathrm{V}_{\mathrm{i}}^{\mathrm{k}}+\mathrm{c} 1 \times \mathrm{r} 1 \times\left(\mathrm{Pbest}^{\mathrm{k}}-\mathrm{Xi}^{\mathrm{k}}\right)+\mathrm{c} 2 \times \mathrm{r} 2 \times\left(\text { gbest }^{\mathrm{k}}-\mathrm{Xi}^{\mathrm{k}}\right)\right]
$$

Where $\mathrm{K}$ is the constriction factor and given by:

$$
\mathrm{K}=\frac{2}{\left|2-\varphi-\sqrt{\varphi^{2}-4 \varphi}\right|}
$$

Where: $\varphi=\mathrm{c} 1+\mathrm{c} 2, \varphi>4$

The convergence characteristic of the particle swarm optimization technique can be controlled by $\varphi$. In the constriction factor approach, $\varphi$ must be greater than 4.0 to guarantee the stability of the PSO algorithm. However, as $\varphi$ increases the constriction factor decreases and diversification is reduced, yielding slower response. Typically, when the constriction factor is used, $\varphi$ is set to 4.1 (i.e. $\mathrm{c}_{1}=\mathrm{c}_{2}=2.05$ ) and the constant multiplier $\mathrm{k}$ is 0.729 . The constriction factor approach can generate higher quality solutions than the basic PSO technique.

VIII. ALGORITHM FOR SHORT TERM HYDROTHERMAL SCHEDULING PROBLEM USING CFPSO TECHNIQUE

The sequential steps of solving short term hydro thermal scheduling problem by using genetic algorithm are explained as follows: 
Step 1: Read the system input data, namely fuel cost curve coefficients, power generation limits of hydro and thermal units, number of thermal units, number of hydro units, power demands, water discharge rate coefficients, amount of water available in hydro reservoir, transmission loss coefficients matrix, surface area of reservoir and initial head of reservoir.

Step 2: Select the parameters of PSO such as population size $(\mathrm{Np})$, acceleration constants $\left(\mathrm{c}_{1}\right.$ and $\left.\mathrm{c}_{2}\right)$, initial and final value of inertia weight factor $\left(\omega_{\min }\right.$ and $\left.\omega_{\max }\right)$.

Step 3: Initialize a population of particles with random positions according to the minimum and maximum operating limits of each unit (upper and lower bounds of power output of thermal generating units and upper and lower bounds of water discharge rate of hydro units). These initial particles must be feasible candidate solutions that satisfy the practical operation constraints of all thermal and hydro units.

Step 4: Initialize the velocity of particles in the range between $\left[-\mathrm{Vi}^{\max },+\mathrm{Vi}^{\mathrm{max}}\right]$.

Step 5: Calculate the power generation of each hydro unit.

Step 6: Calculate the thermal demand by subtracting the generation of hydro units from the total load demand. The thermal demand (total load - hydro generation) must be covered by the thermal units. The thermal generations are calculated from the power balance equation given in (4).

Step 7: Evaluate the variation in water head by using equation (13).

Step 8: Evaluate the fitness value of each particle in the population using the objective function given in (1).

Step 9: If the evaluation value of each particle is better than the previous Pbest, then set Pbest equal to the current value.

Step 10: Select the particle with the best fitness value of all the particles in the population as the gbest.

Step 11: Update the velocity of each particle according to equation (21).

Step 12: Check the velocity of each particle according to the following equation:

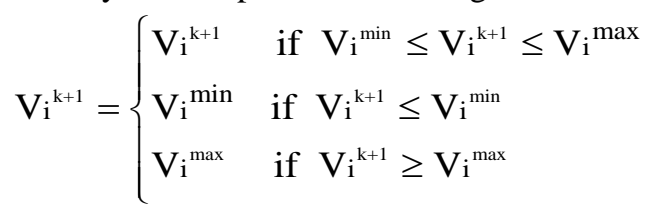

Step 13: The position of each particle is modified according to equation (19).

Step 14: If the stopping criterion is reached (i.e. usually maximum number of iterations) go to step 15 , otherwise go to step 5 .

Step 15: The particle that generates the latest gbest is the optimal generation power of each unit with minimum total fuel cost of the thermal power plants.

Step 16: print the output results and stop.

\section{CASE STUDY AND SIMULATION RESULTS}

To verify the feasibility and effectiveness of the proposed algorithms, a hydrothermal power system consists of two thermal units and two hydro plants were tested. The scheduling time period is one day with 24 intervals of one hour each. The data of test system are taken from [2]. The fuel cost data of the thermal generating units are given in table 1. In this case study, the water discharge rate is represented according to Glimn Kirchmayer model. The rate discharge variations of hydro reservoirs are expressed by using bi-quadratic functions in terms of effective net head and active power generated. The water discharge rate coefficients of hydro power plants are given in table 2 . The hydro reservoirs have small capacity and vertical sides. The water available, surface area of reservoirs, constant of proportionality and initial height of head are given in table 3 . The scheduling time period is one day with 24 intervals of one hour each. The load demand for 24 hours is given in table 4. The B-matrix of the transmission line loss coefficients is given in equation (24). The proposed algorithms has been implemented in MATLAB language and executed on an Intel Core i3, 2.27 GHz personal computer with a 3.0 GB of RAM. The optimal control parameters used in GA are listed in table 5. The PSO control parameters selected for the solution are given in table 6. The program is run 50 times for each algorithm and the best among the 50 runs are taken as the final solutions. The optimal power schedule of thermal and hydro power plants that meets the required load demand and the transmission line losses obtained from the CFPSO method is shown in table 7 while table 8 gives the optimal hydrothermal generation schedule along with demand for 24 hour including the transmission line losses obtained from the GA. Table 9 presents the hourly water discharge rate of hydro power units and the variations of water head in two reservoirs obtained from CFPSO algorithm and Table 10 shows the hourly optimal water discharge rate of hydro units and the variations of water head in each of the two hydro reservoirs obtained from the GA. Table 11 shows the comparison of total fuel cost and computation time between the two proposed methods. From table 11, it is observed that the CFPSO algorithm give the same solution as obtained by GA. Figure 4 shows the optimal power generation schedule of hydrothermal test system using CFPSO method. The hourly hydro plant discharge trajectories by 
using CFPSO method is given in figure 5 while figure 6 presents the variations of water head of the two reservoirs by using CFPSO technique. Figure 7 gives the optimal power generation schedule during day hours by using genetic algorithm; figure 8 shows the hourly hydro plant discharge trajectories by using GA, figure 9 presents the variations of water head of the two reservoirs by using GA. Figure 10 shows the convergence characteristic of CFPSO algorithm for the test case study while figure 11gives the convergence characteristic of GA for the test system considered. From figure 10 it is seen that the convergence characteristic of CFPSO technique is faster and smooth compared to GA method.

Table 1: Fuel cost data of thermal generating power plants

\begin{tabular}{|c|c|c|c|}
\hline Plant & $\mathrm{a}_{\mathrm{i}}\left(\$ / \mathrm{MW}^{2} \mathrm{hr}\right)$ & $\mathrm{b}_{\mathrm{i}}(\$ / \mathrm{MWhr})$ & $\mathrm{c}_{\mathrm{i}}(\$ / \mathrm{hr})$ \\
\hline 1 & 0.0025 & 3.20 & 25.00 \\
\hline 2 & 0.0008 & 3.40 & 30.00 \\
\hline
\end{tabular}

Table 2: Discharge rate coefficients of hydro power plants

\begin{tabular}{|c|c|c|c|c|c|c|}
\hline Plant & $\mathrm{x}_{\mathrm{j}}$ & $\mathrm{y}_{\mathrm{j}}$ & $\mathrm{zj}_{\mathrm{j}}$ & $\alpha_{\mathrm{j}}$ & $\beta_{\mathrm{j}}$ & $\gamma_{\mathrm{j}}$ \\
\hline 1 & 0.000216 & 0.306 & 0.198 & 0.00001 & -0.0030 & 0.90 \\
\hline 2 & 0.000360 & 0.612 & 0.936 & 0.00002 & -0.0025 & 0.95 \\
\hline
\end{tabular}

Table 3: Reservoir data of variable head hydro power plants

\begin{tabular}{|c|c|c|c|c|}
\hline Plant & Water volume $\left(\mathrm{Mft}^{3}\right)$ & Surface area $\left(\mathrm{Mft}^{2}\right)$ & Initial height $(\mathrm{ft})$ & Constant \\
\hline 1 & 2850.00 & 1000.00 & 300.00 & 1.00 \\
\hline 2 & 2450.00 & 400.00 & 250.00 & 1.00 \\
\hline
\end{tabular}

Table 4: Load demand for 24 hour

\begin{tabular}{|c|c|c|c|c|c|c|c|}
\hline Hour & PD $(\mathrm{MW})$ & Hour & PD $(\mathrm{MW})$ & Hour & PD $(\mathrm{MW})$ & Hour & PD $(\mathrm{MW})$ \\
\hline 1 & 800 & 7 & 800 & 13 & 1300 & 19 & 1430 \\
\hline 2 & 750 & 8 & 1000 & 14 & 1350 & 20 & 1350 \\
\hline 3 & 700 & 9 & 1330 & 15 & 1350 & 21 & 1270 \\
\hline 4 & 700 & 10 & 1350 & 16 & 1370 & 22 & 1150 \\
\hline 5 & 700 & 11 & 1450 & 17 & 1450 & 23 & 1000 \\
\hline 6 & 750 & 12 & 1500 & 18 & 1570 & 24 & 900 \\
\hline
\end{tabular}

Table 5: Control parameters of genetic algorithm (GA)

\begin{tabular}{|c|c|}
\hline Genetic algorithm parameters & Value \\
\hline Population size & 50 \\
\hline Maximum number of generations & 300 \\
\hline Crossover probability & 0.8 \\
\hline Mutation probability & 0.05 \\
\hline
\end{tabular}

Table 6: Control parameters of CFPSO technique

\begin{tabular}{|c|c|}
\hline Parameters of CFPSO technique & Value \\
\hline Population size & 50 \\
\hline Maximum number of generations & 300 \\
\hline Acceleration coefficients $\left(\mathrm{c}_{1} / \mathrm{c}_{2}\right)$ & 2.05 \\
\hline Minimum inertia weight $\left(\omega_{\min }\right)$ & 0.4 \\
\hline Maximum inertia weight $\left(\omega_{\max }\right)$ & 0.9 \\
\hline Constriction factor $(\mathrm{k})$ & 0.729 \\
\hline
\end{tabular}

$$
\mathrm{Bij}=10^{-3}\left[\begin{array}{cccc}
0.140 & 0.010 & 0.015 & 0.015 \\
0.010 & 0.060 & 0.010 & 0.013 \\
0.015 & 0.010 & 0.068 & 0.065 \\
0.015 & 0.013 & 0.065 & 0.070
\end{array}\right] \mathrm{MW}^{-1}
$$


Table 7: Hourly optimal hydrothermal generation schedule and power loss using CFPSO technique

\begin{tabular}{|c|c|c|c|c|c|c|}
\hline \multirow{2}{*}{ Hour } & \multicolumn{2}{|c|}{ Thermal generation, MW } & \multicolumn{2}{|c|}{ Hydro generation, MW } & \multirow{2}{*}{ Loss (MW) } & \multirow{2}{*}{$\begin{array}{l}\text { Total fuel cost } \\
\text { (\$) }\end{array}$} \\
\hline & $\mathrm{Pg}_{1}$ & $\mathrm{Pg}_{2}$ & $\mathrm{Ph}_{1}$ & $\mathrm{Ph}_{2}$ & & \\
\hline 1 & 152.4248 & 363.8648 & 270.4755 & 35.5583 & 22.3234 & 1943.901 \\
\hline 2 & 144.8257 & 338.5783 & 260.0466 & 26.1074 & 19.5580 & 1813.753 \\
\hline 3 & 135.0622 & 315.8243 & 249.7131 & 16.3725 & 16.9721 & 1686.402 \\
\hline 4 & 134.9919 & 315.7188 & 249.7953 & 16.4658 & 16.9718 & 1685.718 \\
\hline 5 & 134.8697 & 315.6251 & 249.9371 & 16.5392 & 16.9711 & 1684.878 \\
\hline 6 & 144.6575 & 338.4855 & 260.2032 & 26.2109 & 19.5571 & 1812.727 \\
\hline 7 & 151.8314 & 364.4496 & 271.2132 & 34.8247 & 22.3189 & 1943.880 \\
\hline 8 & 185.0214 & 468.8102 & 317.2587 & 64.2852 & 35.3755 & 2502.432 \\
\hline 9 & 242.7784 & 639.0795 & 388.3615 & 123.9886 & 64.2080 & 3478.853 \\
\hline 10 & 246.1715 & 647.7730 & 393.5562 & 128.7538 & 66.2545 & 3532.366 \\
\hline 11 & 262.6850 & 701.1779 & 414.5501 & 148.6341 & 77.0471 & 3845.426 \\
\hline 12 & 271.7323 & 726.3529 & 425.6139 & 159.0867 & 85.7858 & 4000.810 \\
\hline 13 & 236.9067 & 619.8458 & 381.5476 & 122.8949 & 61.1950 & 3368.256 \\
\hline 14 & 245.0913 & 645.3309 & 391.9764 & 133.8559 & 66.2545 & 3516.753 \\
\hline 15 & 244.8648 & 645.2341 & 392.1936 & 133.9605 & 66.2530 & 3515.322 \\
\hline 16 & 246.9909 & 654.3519 & 396.6148 & 140.3776 & 68.3352 & 3565.220 \\
\hline 17 & 261.9011 & 694.9214 & 412.3682 & 157.8612 & 77.0519 & 3813.629 \\
\hline 18 & 281.1182 & 758.6118 & 436.9817 & 184.5065 & 91.2182 & 4191.821 \\
\hline 19 & 256.2512 & 680.9558 & 409.6527 & 157.9542 & 74.8139 & 3725.376 \\
\hline 20 & 240.2744 & 640.9730 & 387.8577 & 147.1544 & 66.2595 & 3476.193 \\
\hline 21 & 227.6424 & 598.6478 & 373.1062 & 128.8671 & 58.2635 & 3235.114 \\
\hline 22 & 206.3906 & 534.4238 & 345.1361 & 111.3851 & 47.3356 & 2867.471 \\
\hline 23 & 180.2835 & 457.5829 & 315.6748 & 81.8380 & 35.3792 & 2436.450 \\
\hline 24 & 164.4228 & 405.3908 & 294.6726 & 63.9661 & 28.4523 & 2158.542 \\
\hline
\end{tabular}

Table 8: Hourly optimal hydrothermal generation schedule and power loss using genetic algorithm

\begin{tabular}{|c|c|c|c|c|c|c|}
\hline \multirow{2}{*}{ Hour } & \multicolumn{2}{|c|}{ Thermal generation, MW } & \multicolumn{2}{c|}{ Hydro generation, $\mathrm{MW}$} & \multirow{2}{*}{ Loss (MW) } & Total fuel cost \\
\cline { 2 - 5 } & $\mathrm{Pg}_{1}$ & $\mathrm{Pg}_{2}$ & $\mathrm{Ph}_{1}$ & $\mathrm{Ph}_{2}$ & & \\
\hline 1 & 149.1377 & 366.4161 & 275.6650 & 31.0812 & 22.3000 & 1941.069 \\
\hline 2 & 141.4647 & 340.5243 & 265.7296 & 21.8158 & 19.5344 & 1808.266 \\
\hline 3 & 133.2488 & 317.0635 & 254.6081 & 12.0385 & 16.9589 & 1684.224 \\
\hline 4 & 133.2269 & 316.9557 & 254.6666 & 12.1096 & 16.9588 & 1683.718 \\
\hline 5 & 133.1172 & 316.7523 & 254.8776 & 12.2113 & 16.9584 & 1682.499 \\
\hline 6 & 141.1182 & 340.2956 & 265.9563 & 22.1628 & 19.5329 & 1806.010 \\
\hline 7 & 148.9783 & 366.2095 & 275.8455 & 31.2661 & 22.2994 & 1939.617 \\
\hline 8 & 183.8402 & 470.2476 & 315.8926 & 65.3918 & 35.3722 & 2503.530 \\
\hline 9 & 239.7112 & 642.9393 & 385.5812 & 125.9755 & 64.2072 & 3482.420 \\
\hline 10 & 243.2122 & 651.9149 & 390.1832 & 130.9456 & 66.2559 & 3537.665 \\
\hline 11 & 258.4798 & 706.0293 & 411.3920 & 151.1482 & 77.0493 & 3848.446 \\
\hline 12 & 267.8739 & 731.1036 & 422.2654 & 161.5473 & 82.7920 & 4004.950 \\
\hline 13 & 233.2832 & 623.3386 & 378.0462 & 126.5245 & 61.1923 & 3367.750 \\
\hline 14 & 243.0513 & 649.3636 & 387.6023 & 136.2445 & 66.2617 & 3525.624 \\
\hline 15 & 242.6979 & 648.5832 & 388.1235 & 136.8539 & 66.2585 & 3520.600 \\
\hline 16 & 245.9637 & 654.1714 & 393.4652 & 144.7426 & 68.3429 & 3559.864 \\
\hline 17 & 259.5523 & 697.5212 & 409.8923 & 160.0875 & 77.0533 & 3814.787 \\
\hline 18 & 279.4619 & 760.3069 & 437.7947 & 183.6474 & 91.2109 & 4192.022 \\
\hline 19 & 253.9684 & 683.4909 & 408.1237 & 159.2288 & 74.8118 & 3726.546 \\
\hline 20 & 239.8322 & 642.1165 & 389.3057 & 144.9978 & 66.2522 & 3479.309 \\
\hline 21 & 225.5682 & 600.0524 & 371.8717 & 130.7687 & 58.2610 & 3232.249 \\
\hline 22 & 204.6546 & 535.4057 & 346.6037 & 110.6628 & 47.3268 & 2864.310 \\
\hline 23 & 178.6635 & 460.3584 & 314.8918 & 81.4562 & 35.3699 & 2441.287 \\
\hline 24 & 162.7397 & 406.1174 & 294.3961 & 65.1935 & 28.4467 & 2154.722 \\
\hline & & & & & 1018 \\
\hline
\end{tabular}


Table 9: Hourly hydro plant discharge and variation of water head of the two reservoirs using CFPSO technique

\begin{tabular}{|c|c|c|c|c|}
\hline \multirow{2}{*}{ Hour } & \multicolumn{2}{|c|}{ Hydro discharges $\left(\mathrm{Mft}^{3} / \mathrm{hr}\right)$} & \multicolumn{2}{|c|}{ Net head (ft) } \\
\hline & $\mathrm{qh}_{1}$ & $\mathrm{qh}_{2}$ & $\mathrm{~h}_{1}$ & $\mathrm{~h}_{2}$ \\
\hline 1 & 88.8889 & 36.4658 & 300.0000 & 250.0000 \\
\hline 2 & 84.9160 & 27.0139 & 299.9111 & 249.9088 \\
\hline 3 & 81.0244 & 17.3945 & 299.8262 & 249.8412 \\
\hline 4 & 81.0331 & 17.4825 & 299.7452 & 249.7977 \\
\hline 5 & 81.0640 & 17.5509 & 299.6642 & 249.7540 \\
\hline 6 & 84.8818 & 27.0920 & 299.5832 & 249.7101 \\
\hline 7 & 89.0209 & 35.6686 & 299.4983 & 249.6423 \\
\hline 8 & 106.9077 & 65.6421 & 299.4093 & 249.5531 \\
\hline 9 & 136.1367 & 129.3266 & 299.3024 & 249.3889 \\
\hline 10 & 138.2892 & 134.3803 & 299.1663 & 249.0656 \\
\hline 11 & 147.2761 & 156.3206 & 299.0280 & 248.7296 \\
\hline 12 & 152.0401 & 167.8355 & 298.8808 & 248.3388 \\
\hline 13 & 132.9933 & 127.2299 & 298.7287 & 247.9191 \\
\hline 14 & 137.3543 & 139.0605 & 298.5958 & 247.6010 \\
\hline 15 & 137.3842 & 138.9460 & 298.4584 & 247.2533 \\
\hline 16 & 139.2066 & 145.7954 & 298.3211 & 246.9059 \\
\hline 17 & 145.9174 & 165.0288 & 298.1819 & 246.5414 \\
\hline 18 & 156.6189 & 194.9985 & 298.0360 & 246.1288 \\
\hline 19 & 144.5978 & 164.4288 & 297.8794 & 245.6413 \\
\hline 20 & 135.2176 & 152.1052 & 297.7348 & 245.2302 \\
\hline 21 & 128.9619 & 131.8373 & 297.5996 & 244.8499 \\
\hline 22 & 117.3957 & 112.8934 & 297.4707 & 244.5202 \\
\hline 23 & 105.5559 & 81.8817 & 297.3533 & 244.2380 \\
\hline 24 & 97.3184 & 63.6210 & 297.2477 & 244.0332 \\
\hline
\end{tabular}

Table 10: Hourly hydro plant discharge and variation of water head of the two reservoirs using genetic algorithm

\begin{tabular}{|c|c|c|c|c|}
\hline \multirow{2}{*}{ Hour } & \multicolumn{2}{|c}{ Hydro discharges $\left(\mathrm{Mft}^{3} / \mathrm{hr}\right)$} & \multicolumn{2}{c|}{ Net head $(\mathrm{ft})$} \\
\cline { 2 - 5 } & $\mathrm{qh}_{1}$ & $\mathrm{qh}_{2}$ & $\mathrm{~h}_{1}$ & $\mathrm{~h}_{2}$ \\
\hline 1 & 90.8690 & 31.9811 & 300.0000 & 250.0000 \\
\hline 2 & 87.0608 & 22.7636 & 299.9092 & 249.9200 \\
\hline 3 & 82.8502 & 13.1517 & 299.8221 & 249.8631 \\
\hline 4 & 82.8492 & 13.2191 & 299.7393 & 249.8302 \\
\hline 5 & 82.9053 & 13.3164 & 299.6564 & 249.7971 \\
\hline 6 & 87.0493 & 23.0894 & 299.5736 & 249.7637 \\
\hline 7 & 90.7827 & 32.1209 & 299.4865 & 249.7060 \\
\hline 8 & 106.3596 & 66.8107 & 299.3958 & 249.6256 \\
\hline 9 & 134.9496 & 131.5606 & 299.2894 & 249.4586 \\
\hline 10 & 136.8450 & 136.8467 & 299.1545 & 248.7875 \\
\hline 11 & 145.8987 & 159.1980 & 299.0177 & 248.3895 \\
\hline 12 & 150.5669 & 170.6736 & 298.8718 & 247.9627 \\
\hline 13 & 131.5150 & 131.2294 & 298.7212 & 247.6346 \\
\hline 14 & 135.4927 & 141.7211 & 298.5897 & 247.2803 \\
\hline 15 & 135.6529 & 142.1555 & 298.4543 & 246.9249 \\
\hline 16 & 137.8619 & 150.6503 & 298.3186 & 246.5482 \\
\hline 17 & 144.8457 & 167.5399 & 298.1808 & 246.1293 \\
\hline 18 & 156.9787 & 194.0100 & 298.0360 & 245.6443 \\
\hline 19 & 143.9381 & 165.8591 & 297.8790 & 245.2296 \\
\hline 20 & 135.8306 & 149.7235 & 297.7351 & 244.8552 \\
\hline 21 & 128.4471 & 133.9025 & 297.5993 & 244.5204 \\
\hline 22 & 117.9923 & 112.1266 & 297.4708 & 244.0363 \\
\hline 23 & 105.2469 & 81.4901 & 297.2476 & \\
\hline 24 & 97.2116 & 64.8594 & & \\
\hline
\end{tabular}


Variable Head Hydrothermal Generation Scheduling Using Genetic Algorithm and Constriction Fac

Table 11: comparison of total fuel cost and computation time between GA and CFPSO techniques

\begin{tabular}{|c|c|c|}
\hline Method & Total fuel cost $(\$)$ & CPU Time (Sec) \\
\hline CFPSO & 69801.292 & 12.47 \\
\hline GA & 69801.482 & 22.63 \\
\hline
\end{tabular}

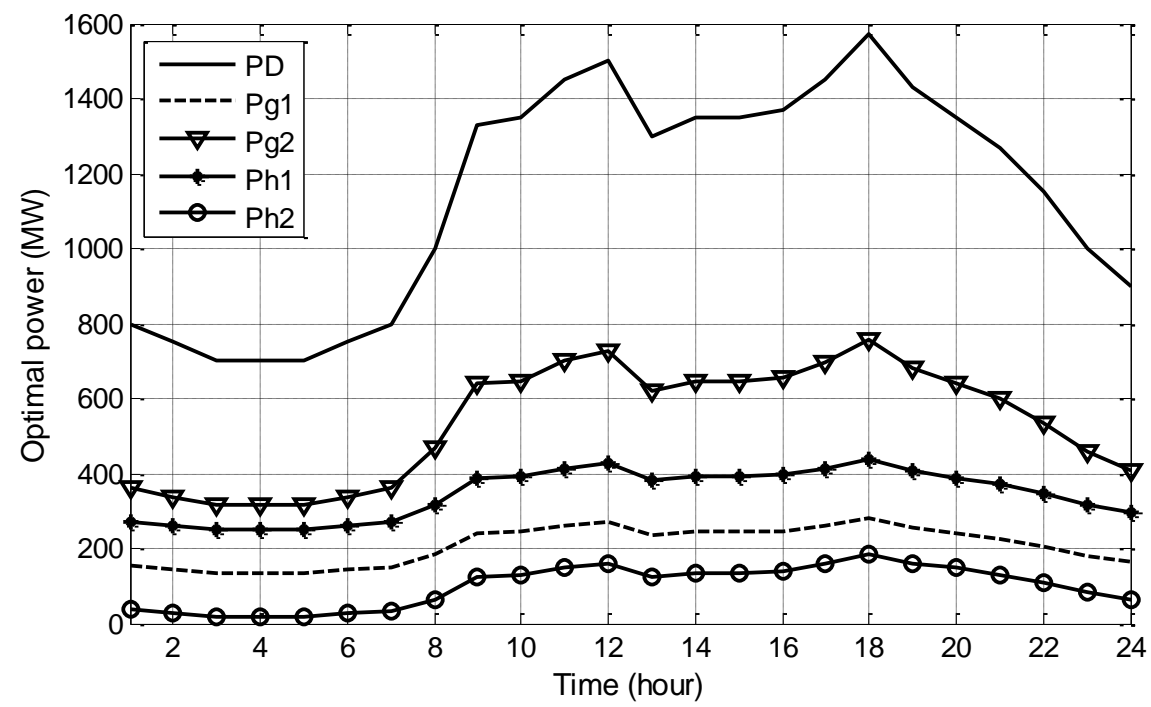

Fig.4. Optimal power generation schedule using CFPSO technique

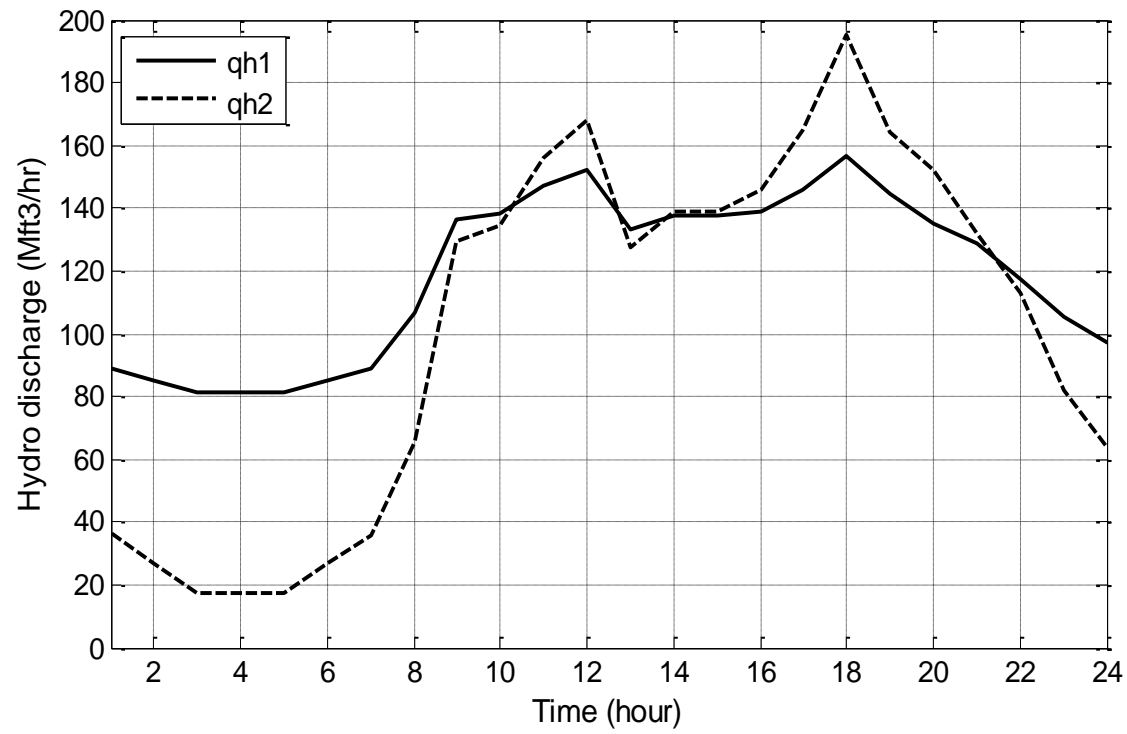

Fig.5. Hydro plant discharge trajectories using CFPSO technique 


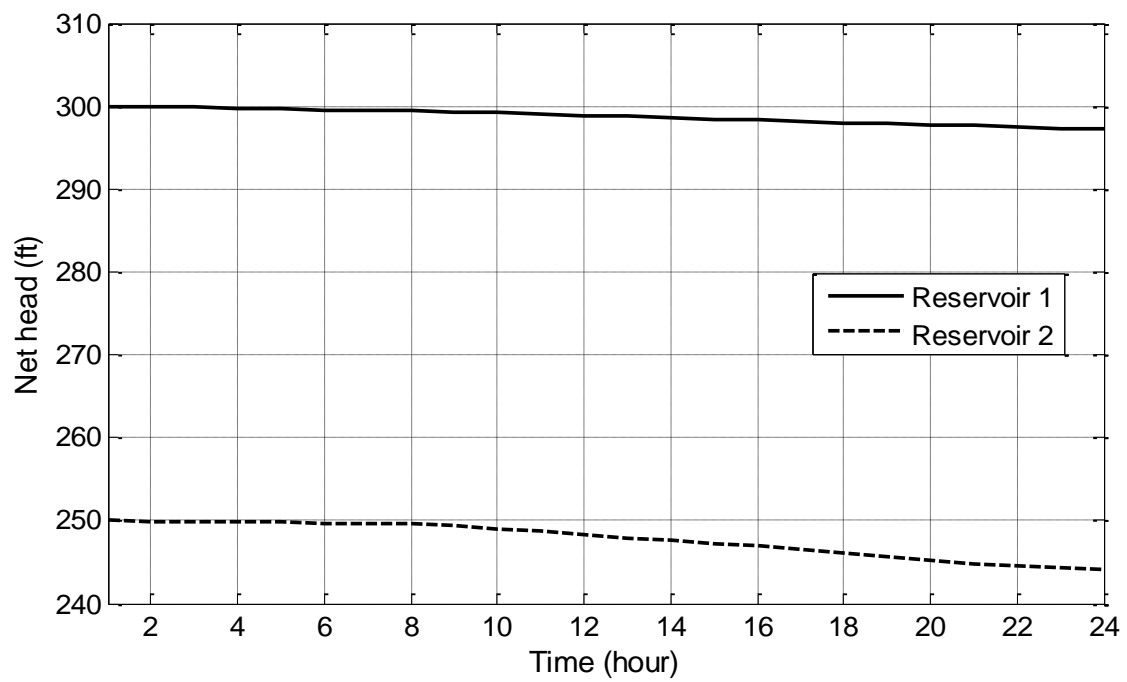

Fig.6. Water head variations of two reservoirs using CFPSO technique

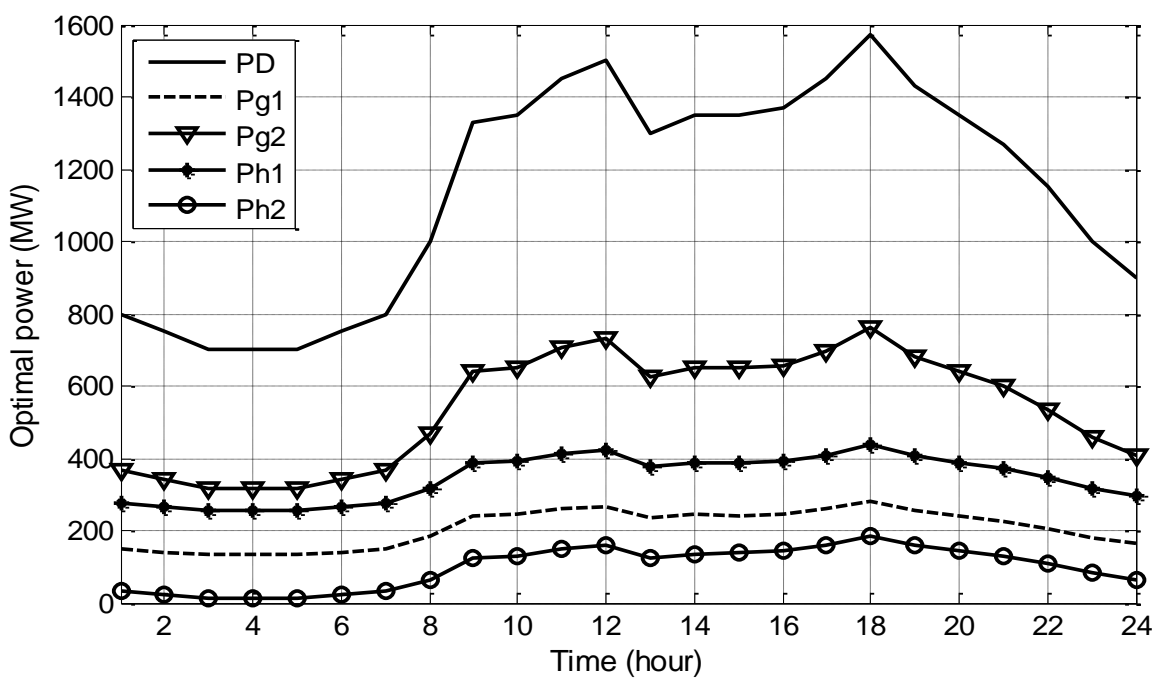

Fig.7. Optimal power generation schedule using GA method

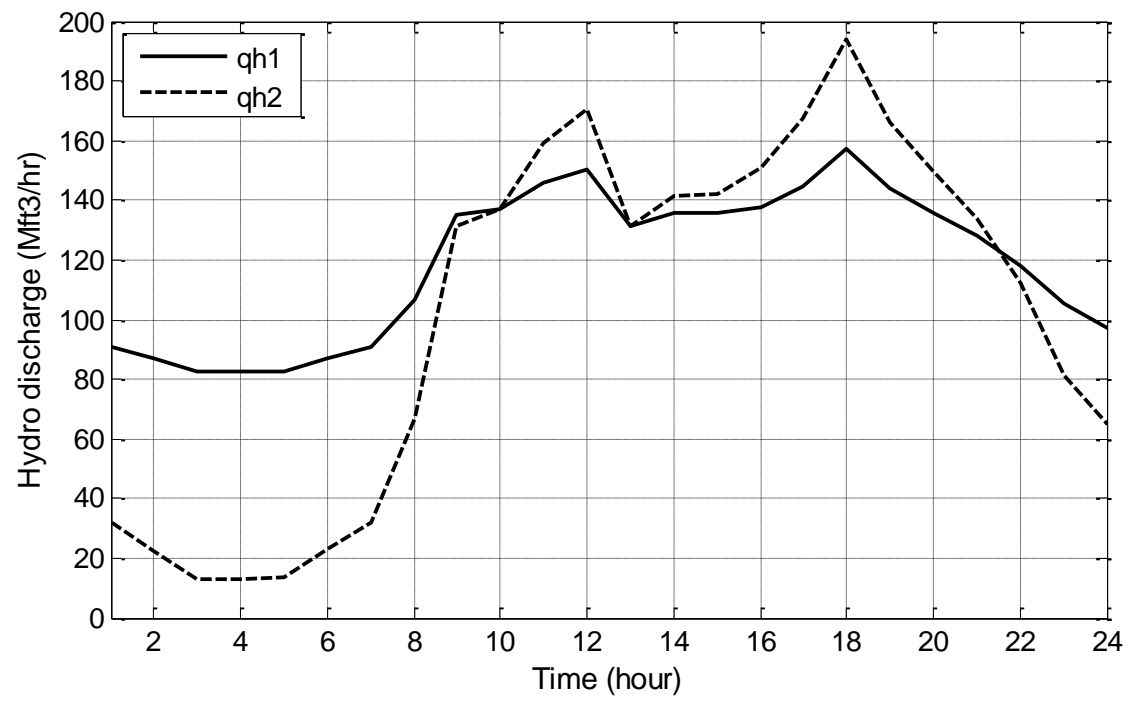

Fig.8. Hydro plant discharge trajectories using GA method 


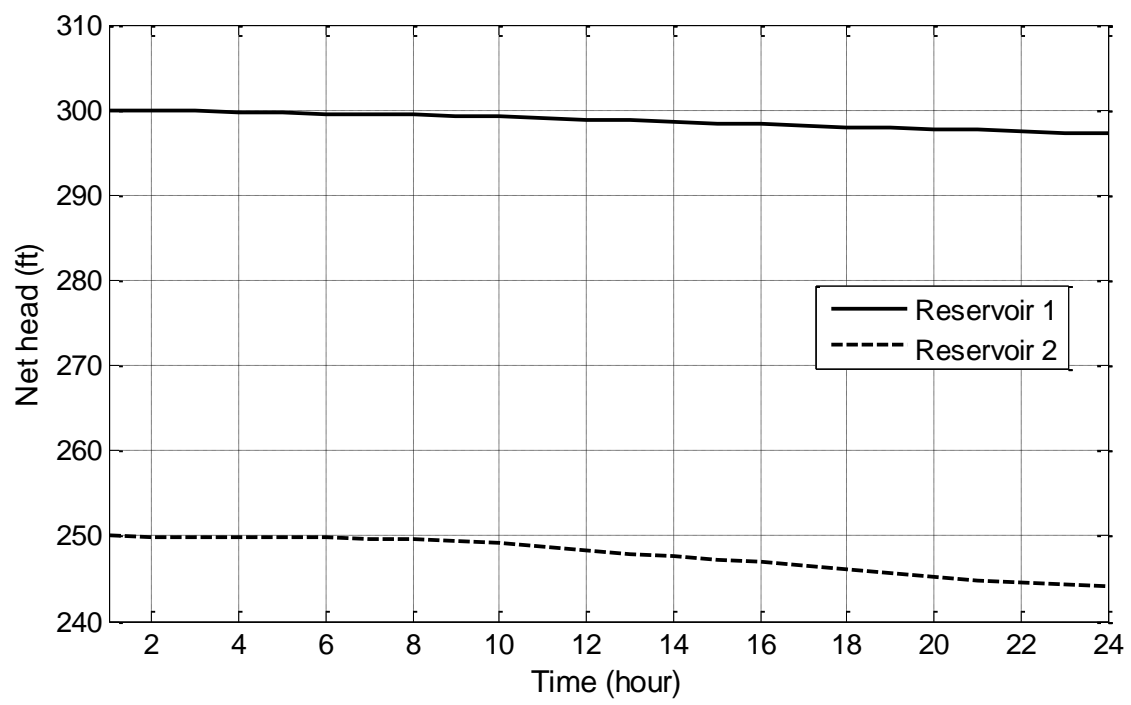

Fig.9. Water head variations of two reservoirs using GA method

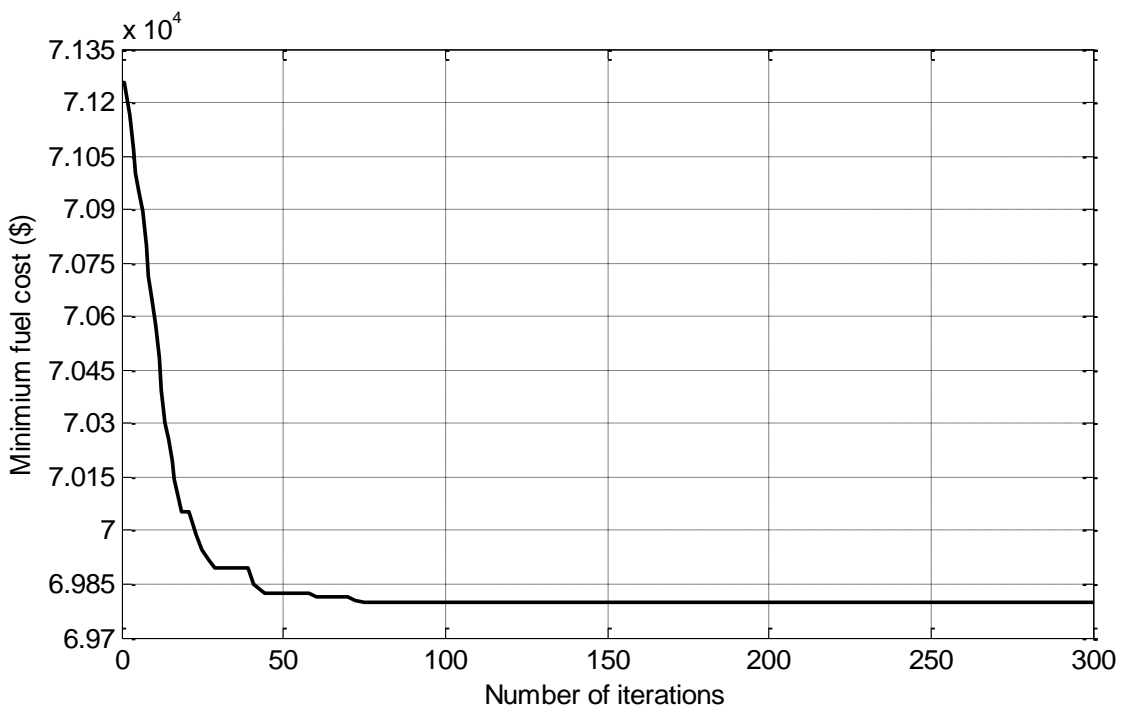

Fig.10. Convergence characteristic of CFPSO technique for the test case study

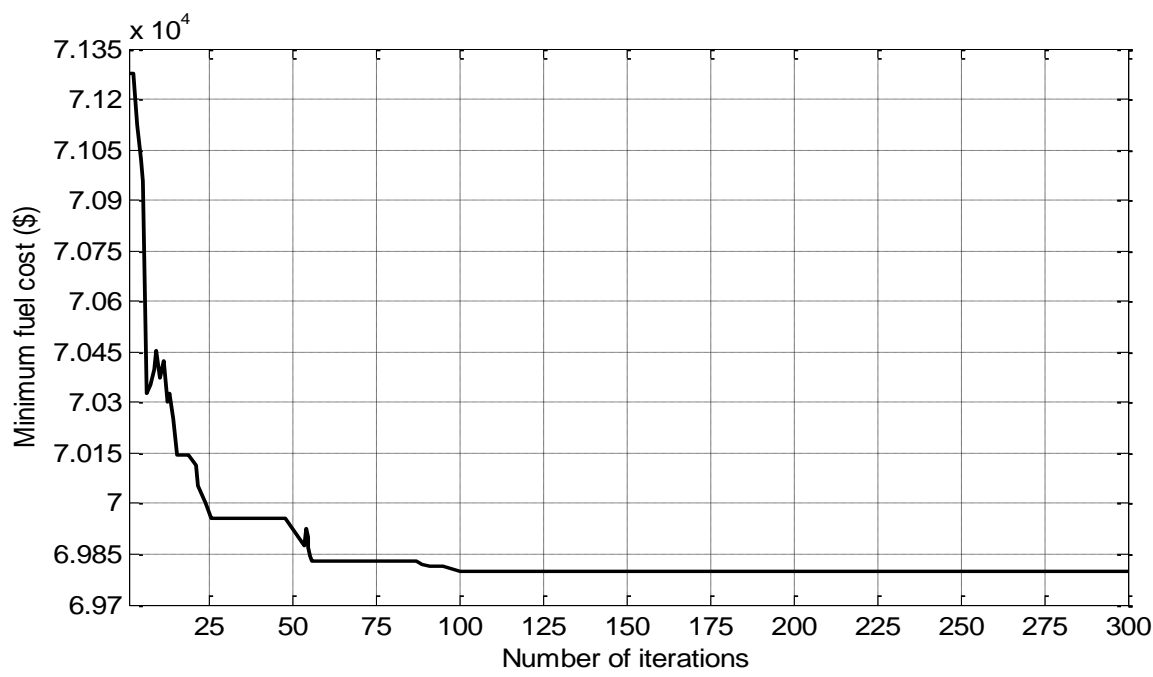

Fig.10. Convergence characteristic of GA method for the test case study 


\section{CONCLUSION}

In this paper, particle swarm optimization technique with constriction factor and genetic algorithm are proposed for solving short term variable head hydrothermal scheduling problem. To demonstrate the performance efficiency of the proposed algorithms, they has been applied on hydrothermal system consists of two thermal units and two hydro power plants. In this paper, the transmission line losses are taken into account. The results obtained from the constriction factor based particle swarm optimization technique are compared with the simulation results obtained from the genetic algorithm to verify the feasibility of the proposed methods. The numerical results show that the particle swarm optimization with constriction factor gives the same results as obtained by the genetic algorithm. From the tabulated results, it is clear that the genetic algorithm require more computation time than the constriction factor based particle swarm optimization technique. Thus, the CFPSO approach can converge to the minimum fuel cost faster than the GA.

\section{REFERENCES}

[1] A.J. Wood and B.F. Wollenberg, "Power Generation, Operation, and Control", John Wiley and Sons., New York, 1984.

[2] D.P. Kothari and J.S. Dhillon, "Power system optimization", New Delhi, India, Pvt. Ltd, 2009.

[3] I.A. Farhat and M.E. El-Hawary, "Optimization methods applied for solving the short term hydro thermal coordination problem", Electric Power System Research, vol. 79, pp. 1308-1320, 2009

[4] J. Tang and P.B. Luh, "Hydro thermal scheduling via extended differential dynamic programming and mixed coordination", IEEE Trans. Power Syst., vol. 10, no. 4 pp. 2021-2028, Nov.,1995.

[5] Y. Jin-Shyr and C. Nanming, "Short term hydro thermal coordination using multi pass dynamic programming", IEEE Trans. Power Syst., vol. 4, pp. 1050-1056, 1989.

[6] X. Guan, E. Ni, R. Li and P.B. Luh," An optimization based algorithm for scheduling hydro thermal power systems with cascaded reservoirs and discrete hydro constraints", IEEE Trans. Power Syst., vol. 12, pp. 1775-1780, 1997.

[7] S. Al-Agtash, "Hydro thermal scheduling by augmented lagrangian: consideration of transmission constraints and pumped storage units", Power Engineering Review, IEEE, vol. 21, pp. 58-59, 2001.

[8] O. Nilsson and D. Sjelvgren, "Mixed integer programming applied to short term planning of a hydro thermal system", IEEE Trans. Power Syst., vol. 11, pp. 281-286, 1996.

[9] L.M. Kimball, K.A. Clements, P.W. Davis and I. Nejdawi, "Multi period hydro thermal economic dispatch by an interior point method", Mathematical Problems in Engineering, vol. 8, pp. 33-42, 2002.

[10] J. Maturana, M-C. Riff," Solving the short-term electrical generation scheduling problem by an adaptive evolutionary approach", European Journal of Operational Research, vol. 179, pp. 677-691, 2007.

[11] N.C. Nayak and C.C.A. Rajan, "Hydro thermal scheduling by an evolutionary programming method with cooling-banking constraints", International Journal of Soft Computing and Engineering (IJSCE), Issue .3, vol. 2, pp. 517-521, July, 2012.

[12] D.P. Wong and Y.W. Wong, "Short term hydro thermal scheduling part. I. Simulated annealing approach", Generation, Transmission and Distribution, IEE Proceeding, vol. 141, pp. 497-501, 1994.

[13] D.P. Wong and Y.W. Wong, "Short term hydro thermal scheduling part. II. Parallel simulated annealing approach", Generation, Transmission and Distribution, IEE Proceeding, vol. 141, pp. 502-506, 1994.

[14] D. Yadav, V. Sharma and R. Naresh, "Fixed Head Hydro Thermal Generation Scheduling Using Differential Evolution", Asian Journal of Current Engineering and Maths, pp. 17-23, Jan-Feb, 2013.

[15] V.N. Diew and W. Ongsakul, "Enhanced merit order and augmented lagrange Hopfield network for hydro thermal scheduling", International Journal of Electrical Power \& Energy Systems, vol. 30, no. 2, pp. 93-101, 2008.

[16] V. Sharma, R. Naresh, Sushil and D. Yadav, "Optimal Hydro-Thermal Generation Scheduling Using an Efficient Feedback Neural Network Optimization Model", Research Journal of Applied Sciences, Engineering and Technology, vol. 8, no. 3, pp. 770-778, June, 2011.

[17] E. Gil, J. Bustos and H. Rudnick," Short term hydrothermal generation scheduling model using genetic algorithm", IEEE Trans. Power Syst. Vol. 18, no. 4, pp. 1256-1264, Nov., 2003.

[18] C.E. Zoumas, A.G. Bakirtzis, J.B. Theocharis, V. Petridis," A genetic algorithm solution approach to the hydro thermal coordination problem", IEEE Trans. Power Syst., vol. 19, no. 2, pp. 1356-1364, May, 2004.

[19] A. George, M.C. Reddy and A.Y. Sivaramakrishnan, "Short term hydro thermal scheduling based on multi-objective genetic algorithm", International Journal of Electrical Engineering, vol. 3, no. 1, pp. 1326, 2010.

[20] S. Titus and A.E. Jeyakumar," Hydrothermal scheduling using an improved particle swarm optimization technique considering prohibited operating zones", International Journal of Soft Computing, vol. 2, no. 2, pp. 313-319, 2007. 
[21] G. Sreenivasan, C.H. Saibabu and S. Sivanagaraju," PSO based short-term hydrothermal scheduling with prohibited discharge zones", International Journal of Advanced Computer Science and Applications, vol. 2, no. 9, pp. 97-105, 2011.

[22] C. Sun and S. Lu, "Short term combined economic emission hydro thermal scheduling using improved quantum-behaved particle swarm optimization", Expert Syst. App., vol. 37, pp. 4232-4241, 2010.

[23] K.K. Mandal and N. Chakraborty, "Optimal scheduling of cascaded hydro thermal systems using a new improved particle swarm optimization technique", Smart Grid and Renewable Energy, vol.2, pp. 282292, Aug., 2011.

[24] K.K. Mandal, M. Basu and N. Chakraborty, "Particle swarm optimization technique based short-term hydrothermal scheduling", Applied Soft Computing, pp. 1392-1399,2008.

[25] J.A. Momoh, M.E. El-Hawary and R. Adapa, A review of selected optimal power flow literature to 1993, Part 1,"Non linear and quadratic programming approaches", IEEE Trans. Power Syst., vol. 14, no. 1, PP. 96-104, 1999.

[26] Y. Shi and R.C. Eberhart, "Parameters selection in particle swarm optimization", Proceedings, of the Seventh Annual Conference on Evolutionary Programming, IEEE Press (1998).

[27] M. Clerc and J. Kennedy, "The particle swarm-explosion, stability, and convergence in a multidimensional complex space", IEEE Trans. on Evolutionary Computation, vol. 6, no. 1, pp. 58-73, Feb. 2002. 